\title{
Correction to: Injury Incidence, Prevalence and Severity in High-Level Male Youth Football: A Systematic Review
}

\author{
Steven Jones ${ }^{1,3} \cdot$ Sania Almousa ${ }^{1} \cdot$ Alistair Gibb $^{3} \cdot$ Nick Allamby $^{3} \cdot$ Rich Mullen $^{1} \cdot$ Thor Einar Andersen $^{2}$. \\ Morgan Williams ${ }^{1}$
}

Published online: 9 September 2019

(c) Springer Nature Switzerland AG 2019

\section{Correction to Sports Medicine https://doi.org/10.1007/s40279-019-01169-8}

Page 1: First Key Point, sentence 2, which previously read:

"High-level youth players seemingly loose large portions of seasonal development time to injury."

should read:

"High-level youth players seemingly lose large portions of seasonal development time to injury."

The original article has been corrected.

The original article can be found online at https://doi.org/10.1007/ s40279-019-01169-8.

Steven Jones

s.k.jones@hotmail.co.uk

1 School of Health, Sport and Professional Practice, Faculty of Life Sciences and Education, University of South Wales, Pontypridd, UK

2 Department of Sports Medicine, Oslo Sports Trauma Research Center, Norwegian School of Sport Sciences, Oslo, Norway

3 Bolton Wanderers Football Club, Bolton, UK 